\title{
Building a Bigger Table: Networking 101 For Graduate Students
}

\author{
Seo-young Silvia $\mathrm{Kim}^{\dagger}$, Hannah Lebovits ${ }^{\ddagger}$, and Sarah Shugars ${ }^{*}$ \\ ${ }^{\dagger}$ American University \\ ‡University of Texas-Arlington \\ ${ }^{*}$ New York University
}

June 30, 2021

\begin{abstract}
Although the importance of networking is often emphasized to graduate students, straightforward guidance on how to approach this task is typically reliant on individual advisors both knowing and demystifying the discipline's hidden and informal practices. This article provides concrete, point-by-point tips for both junior scholars and their supporters, building on our experiences creating an online communication forum for early-career scholars on the market. Specifically, we suggest a model of community networking focused on robust, cross-rank engagement along dimensions of similar experiences and similar interests. Community networking aims to move beyond individuals angling to get a seat at the table and instead builds a bigger, more inclusive table. While junior scholars must primarily focus on their research rather than expansive service commitments, community networking is ultimately both a service to the discipline and a fruitful strategy for raising one's profile and finding coauthors, colleagues, friends, and allies.
\end{abstract}

Graduate students are typically advised to start networking early in their careers without direct guidance on why, how, when, and where to start these activities. Many aspiring academics neither have much networking experience nor a clear understanding of what "networking" really means, and have only vague, uncomfortable images of strained relationships aimed solely at one's advancement.

However, "start networking" is excellent and essential advice for new academics. Academia requires high-quality scholarly production, but is also fundamentally relational. Getting to know other scholars systematically and thoughtfully is critical for both academic success and producing good scholarship. Although networking requires time and effort-which are precious commodities for a junior scholar-there is a potential to build rich relationships with future coauthors, colleagues, friends, and allies.

This article aims to demystify the idea of networking by clearly explaining its value, form, and 
function and providing concrete, point-by-point tips on how to build an inclusive, communitycentered network. Drawing on our own experiences as junior academics, we focus specifically on conceptualizing a model centered on the ideals of community, inclusion, and consensus. Moreover, we provide seven specific tips to navigate networking for junior scholars and their supporters. Through such community networking, junior scholars can elevate their scholarship while simultaneously improving the discipline for themselves and those around them.

\section{Conceptually Approaching Networking}

Graduate students often feel they are outside the academic community and must wait for somebody to invite them inside. This isolation is typically felt more acutely by students who are the first in their families to pursue a college degree, women and gender minorities, people of color, and others who have been historically excluded from academic spaces. However, graduate students are members of the academic community. Those "waiting to be invited" miss important opportunities to claim space; to invite themselves - and their peers-in. Furthermore, the traditional narrative of networking only fuels this outsider perspective; presenting "networking" as a self-interested act aimed solely at individual advancement through promoting oneself to senior scholars.

Community networking, on the other hand, begins with the belief that you already belong in the academic community. Its primary goal is to create spaces that actively engage, elevate, and include others. By continually building a bigger table, community networking works to ensure that every individual feels both welcomed and empowered to welcome others. In other words, we conceptualize networking as a process of creating and sustaining a public goodcommunitarianism—and a value to all individuals and institutions involved.

Our community networking model is motivated by both the collective and individual shortfalls of traditional networking approaches. While some individuals may garner benefits from utilitarian networking strategies, this approach typically does not move beyond personal impact, leaving systemic concerns and hyper-competitive spaces untouched. Furthermore, the individual benefits of traditional networking are not typically equitably accrued-those with more power and privilege, who more closely fit the traditional model of "an academic" are more likely to engage in and benefit from this type of networking. Finally, exclusive focus on personal advancement can actually limit one's networking success by undermining the benefits of building a well-rounded professional network capable of providing various forms of support.

We therefore recommend that graduate students engage in community networking, focusing their time and effort along two dimensions: similar-experience and similar-interest. Similar-experience networking maps roughly to the traditional idea of "horizontal" networking with academic rank peers, while similar-interest networking is comparable to so-called "vertical" networking with senior scholars. However, the community networking model suggest larger, inclusive spaces, 
rather than strict lines of hierarchical activities with prescriptive formats.

Our model is not exclusive to particular academic ranks and can be applied to people both above, below, and at the same level in the academic hierarchy. It leverages the community spirit of the fellowship of academics who share interests and experiences. It also helps dispel the harmful environment fostered by individuals who might be focused only on their advancement, with intent to harm those who they perceive to be in their way. Community networking efforts remind members that they are not the first nor last students who feel uncertain, awkward, and out of place in an academic setting. We all belong in academia-no matter who you are, you have the power to make someone else feel they belong as well.

Tip \#1: Recognize that you already belong in the academic community and you have the power to make others feel welcome.

The community networking model might sound Utopian. However, our experiences have shown that for scholars who opt-in, the steps to create, nurture, and sustain such settings are systematic and reproducible across many settings. In the following sections, we present concrete advice aimed at graduate students and those who interact with them.

\section{Building a Similar-Experience Network}

\section{Within the Department}

Imagine you are a first-generation and an immigrant Ph.D. student eager to hit the ground running. The first friends you will make are within your department, especially within your cohort, regardless of research interests. Together, you will take classes, solve assignments, lurch through exams, laugh, commiserate, and get to know each other as people and scholars. These colleagues know first-hand what you are going through at any given moment and can be an important source for moral support and validation. Furthermore, you can facilitate each other's learning. Ask each other questions. Thank people who ask questions you were too afraid to ask. Recognize and demonstrate that mistakes are a crucial part of learning. In a healthy department, your fellow students should be a home-ground where you are more comfortable making mistakes. As Uncle Wuffle (1989)'s advice goes, the best tutor is "trial and error, and a lot of help from friends and faculty advisors."

Furthermore, some people in your cohort may become your most trusted coauthors. This is a great way to begin publishing, as the share of coauthored papers is increasing in academia (Metz and Jäckle, 2017). As departmental peers have received identical training to yours, they may share similar academic perspectives and methodological tools. Shared experiences and viewpoints can enable you to share ideas and drafts, and engage in full research endeavors with each other.

Beyond your immediate cohort, work to build relationships with other graduate students within 
your department. Get to know those who are both more senior and more junior-especially if you share research interests. Ask what advice they would give their younger selves or what resources they feel you might need to succeed. As you get closer to the end of your coursework and your dissertation process, these relationships can create a community of support through a Ph.D.'s more frustrating moments. You may also be able to find supportive relationships outside your department/college. For example, if you are interested in Latin American immigrants' political assimilation, you may want to also talk to students and faculty in departments such as sociology or international affairs.

Additionally, consider partnering with departmental leadership in order to better meet student needs. Ask leadership to organize professional development sessions; ask junior faculty to speak about their work and the publishing process; invite senior faculty to share broader insights; organize spaces where senior students can give advice and provide resources to more junior students. While junior scholars should be mindful not to dedicate too much time to service at the expense of their own scholarship, these efforts can simultaneously support your career as well as that of your peers. Again, even at the departmental level, networking does not need to be all about you, but can instead reflect your broader work to build connections between faculty and graduate students of all ranks.

Unfortunately, toxic graduate school environments are not uncommon. These settings are often institutionally and systemically perpetuated and not conducive to this model. In this example, as a first-generation student and an immigrant, you might experience explicit or implicit racism based on your ethnicity. Let's be clear: you should not feel that you must or can shift the department culture. Your first priority should always be maintaining your own physical/mental health, supporting your loved ones, and making the best choices for you and your career.

Ideally, your department includes faculty and staff who actively work towards fostering a favorable atmosphere. Graduate students should not have to shoulder the weight of coordinating a communal network themselves. Instead, the department leadership should create or continue professional development sessions and related opportunities, alleviating the need for students to organize these themselves.

Tip \#2

- Given that the environment is supportive, graduate students should:

- Build relationships within-cohort and with other students in the department.

- Work with department staff and leadership to ensure social events and professional development training best tailored to student needs.

- Supporters and allies should proactively help foster primary relationships and development sessions, alleviating the need for students to organize the opportunities themselves. 


\section{Outside the Department}

Suppose you are now reasonably comfortable navigating within the department and have a set research interest. "Now what?", you may wonder. At this stage, your information source and views of the academia are likely mediated through your advisor. Regardless of how well mentored you may be, it is vital to build a community that extends beyond your university.

Shared-experience connections outside your university might be with people who share your experience as a graduate student or who share your experience in identity groups. Conferences are the most common venue for such networking efforts, and we highly recommend Gupta and Waismel-Manor (2006) for thorough advice on navigating conferences as a graduate student. From a community perspective, such spaces are essential not only for meeting peers but for establishing a broader, multi-institution community of young scholars.

It may feel awkward, phony, or rash to start a conversation with scholars outside your department or university. We suggest setting aside concerns about personal standing or potential embarrassment. While such feelings are entirely understandable, your peers likely feel the same anxiety and hesitation. Your willingness to put yourself out there and begin engaging in communitybuilding efforts will draw other students in through validation and appreciation.

Check if there are pre-conference workshops or sessions explicitly for graduate students. At conference receptions, look for people who are standing alone or in small groups. Ask other graduate students if they have lunch or dinner plans. Make it your mission to find others who feel lost and alone and assure them that they, too, belong. Value every single person you meet and look to connect people-aim to build a community, not merely to further your network.

Building the network outside the department will be a gradual process. Once you find an "entry point"-for example, a Graduate Student Research in Latina/o/x Politics Panel—you will have a few familiar faces at the next conference. You should not expect new acquaintances to have research interests perfectly aligned with your own. For example, they might not focus explicitly on immigrants but on related issues of vote choice. In fact, if you find someone who makes you comfortable showing up in unfamiliar conference socials, there does not have to be a shred of intersection between your research interests! If you approach and keep in touch with them, you will find that venturing outside your university becomes easier over time.

What should the supporters of students do? First, conference participation must be supported, including funding. The selection of the right conferences to start participating in is a key part of advising. Gentle but firm encouragement to seek fellow students out, especially if the student in question is shy, could be good. The supporter's role is more valuable, however, in building the similar-interest network, which we detail in the next section. 
Tip \#3

- Graduate students should:

- Approach fellow graduate students at conferences-they are just as anxious/shy!

- Find and participate in sessions explicitly designed for student networking.

- Supporters should encourage conference participation and direct students to resources for travel funding.

\section{Building a Similar-Interest Network}

Your network does not stop with people who share similar experiences. Get to know academics in your field who share your interests and are a few years ahead, such as Post-Doctoral Fellows or Assistant Professors, and even connect with Associate and Full professors when appropriate. In our running example of an immigrant and a first generation college student studying Latin American immigrants' political assimilation, an interest in immigration and ethnic politics is what frames their interest network.

An excellent place to find your "knowledge-based family" is to find a relevant section or caucus within the profession. Sections can be closely related to your research field and typically have online forums, email listservs and meeting events at major conferences. Caucuses include various APSA Caucuses such as the Latino Caucus, LGBTQ Caucus, Asian Pacific American Caucus, National Conference of Black Political Scientists (NCOBPS), and more. Check out each major conference/regional association to see if there is something that fits your interests. Many sections and caucuses also have travel funding available for graduate students.

Once you have found a caucus/section, see if they have a business meeting or reception scheduled. Such meetings typically come with plenty of socialization opportunities as well as designated panels. These can be huge events, but you need not be shy. Business meetings discuss the group's directions or give out awards such as an Emerging Scholar Award. They are typically open to everyone and are opportunities to get to know people at all levels who are active in your area. Once you have found subgroups with a good fit, you may also consider supporting and organizing their events.

Success in academic networking requires courage and a willingness to reach out to others. You can and should reach out to people of all ranks engaging thoughtfully with their work or requesting individual coffee meetings to received feedback on your projects about four weeks in advance of a conference. You may have internalized imposter syndrome, but these self-images are inaccurate. Note that non-responses or dismissive replies are not a reflection of you. The lack of response has more to do with the sheer volume of emails facing the recipient and should not be taken personally.

The good news is that many academics actively want to support junior scholars, and some do 
this through official channels such as the APSA Mentoring Program Match. They, too, want to build inclusive communities and share their experiences, knowledge, and insights. The challenge is that, while doing this through one-on-one meetings or detailed scholarly feedback can be extremely valuable, such individual interactions do not scale well. There are not enough hours in the day for senior scholars to engage in all possible traditional networking efforts.

The community-based networking model can supply a solution to this resource constraint problem. As the model encourages larger tables and inclusive spaces, the opportunity can produce significant outreach with much less effort. One example of this can be seen in a mentorship network by Dr. Mirya Holman at Tulane University, dubbed Mirya Holman's Aggressive Winning Scholars (https:/ / miryaholman.substack.com). This network includes a regular email newsletter and frequent conference events. Dr. Holman's efforts, though primarily one-way, bring scholars of similar-experience and similar-interest groups together to connect, commiserate, and construct a plan to tackle academia's most significant challenges. Although Dr. Holman's hours are limited, her impact as a supporter is maximized.

\section{Tip \#4}

- Graduate students should:

- Find their "knowledge-based family" through relevant subgroups in the discipline, such as conference caucuses/sections or online forums/listservs.

- Reach out to senior scholars and actively seek mentoring.

- Supporters should seek to rectify the resource constraints on individuals by spreading their own knowledge through larger dissemination platforms.

\section{An Application of the Community-Based Networking Model}

As mentioned, our insight has been shaped by our own experiences as community builders. One such endeavor shared by the authors is establishing an online communication forum (http:/ / supportyourcohort.com), a Slack channel, for early-career scholars on the market. Creating this group took no specialized training or knowledge; merely recognizing a growing need and the willingness to input time and personal stake. The authors-going on the market themselves at the time-felt the need for a supportive, inclusive, non-anonymous, and multi-way communication forum where candidates could share information and support each other through the market process. In the absence of an official resource, we created one. We established a code of conduct for members and provided separate forums for specific interests. Members shared resources, insight, feedback, and knowledge of search updates. It did not alleviate all job market anxiety, but it created a space where members could commiserate and congratulate, rather than going through the difficult process alone.

Support Your Cohort complimented the one-way official APSA eJobs board by providing a 
unique, multi-way communication channel. The platform was intentionally moderated and nonanonymous, thereby serving as a safe space where job market peers could connect.

When we announced the Slack channel's existence on social media, the responses from job market candidates and senior faculty were tremendous and positive. Faculty members across the world quickly encouraged their students to join. They also reached out to the group administrators with information about jobs, graduate student resources, and job market success tips. The membership encompassed both shared-experience and shared-interest groups.

Members almost universally found the Slack channel to be a valuable and supportive space. Frequent posts included well-wishes, congratulatory statements, reminders about mental health resources, and encouragement during tough stretches in the semester. The intentional communitybased network provided relief from the competition that many scholars might naturally feel towards those applying for the same positions. Instead of competing with one another, the aptly named Support your Cohort group built a community.

This is just one example of how community networking can be initiated. The authors have collectively created numerous spaces, including multi-institution support groups, within-department training/orientations, full-fledged conferences, mentoring sessions, socials, and informal resource circles. Across all these settings, the formula is the same: recognize a need, remind yourself that you have the power to fill it, seek out a method that elevates the community, and engage others in doing the work. If you feel out of place at a conference, feel like an imposter, or wish you had more access to information about academia's unspoken norms, someone else does too. Find those others and build support together.

It is not just your graduate peers who share these challenges. Many senior scholars face similar struggles or remember when they did and will be genuinely glad to help support future academic generations. Community networking means having the courage to name these shared struggles and using the power you may not even know you have to ensure others feel welcome, valued, and supported.

Tip \#5

- Graduate students should:

- Create the spaces they would like to see, whether online or in-person.

- Remember you are not alone, and chances are someone else is struggling as well.

- Supporters can assist existing networking efforts and share their own experiences to foster an inclusive environment. 


\section{Lessons from the Pandemic: Virtual Networking and Beyond}

The difficulty of networking increased tremendously due to COVID-19 and the disappearance of in-person opportunities such as conferences. However, it has also highlighted the valuable role online spaces can play in allowing geographically disparate and resource-constrained scholars to connect. Since the onset of the pandemic, several initiatives by brave and compassionate earlycareer scholars have risen to the occasion and are likely to continue as important resources for years to come. The 2019-2020 Support Your Cohort group has morphed into a 2020-2021 forum, spanning close to 650 scholars as of Apr 2021.

Other virtual seminars have also risen to the occasion to support the gap of networking opportunities. The Junior Americanist Workshop Series (JAWS; https://jawspolisci.network) has provided both presentation opportunities for graduate students as well as professional development sessions such as how to publish books and journal articles. Other existing resources have proven extremely valuable - the Women Also Know Stuff (https:/ / www.womenalsoknowstuff.com, or \#womenalsoknowstuff) initiative (Beaulieu et al., 2017) promotes political science research by women, actively celebrating and disseminating new research. The same is true for People of Color Also Know Stuff (https:/ / sites.google.com/view/pocexperts/home, or \#pocalsoknowstuff) initiative. Existing online seminar series such as the Minority Politics Online Seminar Series (MPOSS; https:/ / minoritypolitics.netlify.app) or The International Methods Colloquium (https://www.methods-colloquium.com) continue to provide opportunities to reach a broader audience.

Conferences have also started to provide virtual gathering spaces in the form of virtual coffee or happy hours. If you found some of these to be excruciatingly awkward, you are not alone. Because randomness is reduced in an online setting, it is hard to stumble across someone to begin a more natural conversation. However, understand that virtual gatherings will still serve you better than zero opportunities. For an example of what the complete lack of networking can do to academic collaboration, see Campos, Leon and McQuillin (2018).

Building a social media presence and joining the online community can also be extremely helpful. Twitter will not be the right tool for every person but can be an invaluable opportunity to follow the recent conversations in your subfield, get to know other junior academics, and tap into the broader professional network. Remember that you do not need to jump directly into actively promoting yourself on Twitter-it can be an excellent venue for listening as well as for promoting the work of others. Specifically, we recommend that junior scholars use Twitter as an additional resource to grow their shared-experience and shared interest networks. Rather than aiming to follow influential accounts, use your time on social media to engage with peers and those with substantially overlapping scholarly interests. Look for the people with whom you can connect easily-who could genuinely benefit from your friendship-and grow a community of mutual support. For an overview of how scholars use online tools, see Esarey and Wood (2018). For 
an example of how a group of scholars is working to offset women's under-representation on Twitter, see Beaulieu et al. (2017). These offer insights into how supporters can use online tools to help junior scholars as well.

Tip \#6

- Graduate students should utilize online gatherings and seminar series.

- Supporters should attend students' virtual presentations and offer support via online platforms.

\section{Conclusion}

We believe that demystifying networking as a skill for academic success is a crucial step in democratizing academia. In this paper, we have conceptualized networking through a communitybuilding framework where fellowship and inclusion are the top priorities. Our model builds on the dimensions of similar experiences and similar interests to help graduate students build spaces where they are both welcomed and actively welcoming of others. Based on our own experiences of providing a supportive environment for scholars going on the job market, we provided a set of concrete to-do list for graduate students and junior scholars.

While junior scholars must primarily focus on their research rather than expansive service commitments, community networking is ultimately both a service to the discipline and a fruitful strategy for raising one's profile and finding coauthors, colleagues, friends, and allies. To sustain an inclusive ecosystem, be kind and reciprocate the help you have received-elevate others and pay it forward if you can. No matter who you are, no matter what rank, you have the power to make someone else feel welcome and included. Approach networking not just for selfadvancement but as an opportunity to grow academia and your subfield as a richer, inclusive community.

\section{Tip \#7}

Graduate students should

- Recognize that community building is not a threat to personal achievement.

- Lean on your network and reciprocate the help you have received.

\section{References}

Beaulieu, Emily, Amber E. Boydstun, Nadia E. Brown, Kim Yi Dionne, Andra Gillespie, Samara Klar, Yanna Krupnikov, Melissa R. Michelson, Kathleen Searles and Christina Wolbrecht. 2017. "Women Also Know Stuff: Meta-Level Mentoring to Battle Gender Bias in Political Science." PS: Political Science \& Politics 50(3):779-783. 
Campos, Raquel, Fernanda Leon and Ben McQuillin. 2018. "Lost in the Storm: The Academic Collaborations That Went Missing in Hurricane ISSAC." The Economic Journal 128(610):9951018.

Esarey, Justin and Andrew R. Wood. 2018. "Blogs, Online Seminars, and Social Media as Tools of Scholarship in Political Science." PS: Political Science E Politics 51(4):811-819.

Gupta, Devashree and Israel Waismel-Manor. 2006. "Network in Progress: A Conference Primer for Graduate Students." PS: Political Science \& Politics 39(3):485-490.

Metz, Thomas and Sebastian Jäckle. 2017. "Patterns of Publishing in Political Science Journals: An Overview of Our Profession Using Bibliographic Data and a Co-Authorship Network." PS: Political Science \& Politics 50(1):157-165.

Wuffle, A. 1989. “Uncle Wuffle's Advice to the Advanced Graduate Student." PS: Political Science $\mathcal{E}$ Politics 22(4):838-839. 